\title{
Sexual maturation pattern in the mirror of socioeconomic background
}

\author{
Eva B. Bodzsar and Annamaria Zsakai \\ Department of Biological Anthropology, Eotvos Lorand University, Budapest, Hungary \\ bodzsar@elte.hu
}

With 3 figures and 5 tables

\begin{abstract}
Summary: The inequalities among the socioeconomic strata in the Hungarian society increased during the last decades. Since the socioeconomic conditions play a decisive part in shaping the growth and maturation of children, our purpose was to study the body structure and the growth and maturation pattern of children living in deprived regions in Hungary. Our former analysis revealed that the prevalence of non-normal nutritional status was significantly higher in children and adolescents living in the seriously deprived regions of Hungary than the national reference values. The main purpose of the present study was to compare the sexual maturation pattern of pubertal children living in the deprived regions by comparing the timing of pubertal maturation events to the national reference values. Sexual maturity status of 711 girls and 790 boys (aged 10-16 years) living in the deprived small regions of Hungary was compared to the national reference values (Hungarian National Growth Study II). Sexual maturity status was estimated by the stages of pubic hair, axillary hair, breast and external genitalia development, as well as by the menarcheal and spermarcheal status, respectively. The median ages of being in the pubertal stages of the sexual characteristics, menarcheal and spermarcheal age were estimated by probit analysis. By comparing it to the national reference values, the timing of pubertal development in boys and girls living in the seriously deprived regions showed a 1-3-month shift toward older ages. However, the length of sexual maturation: the interval between the median ages of the first and last pubertal stages of sexual characteristics was similar in the subjects living in the regions of Hungary as the Hungarian reference values.
\end{abstract}

Key words: puberty, sexual maturation, menarche, spermarche, sexual characteristics, socioeconomic background, disadvantaged micro-regions of Hungary.

\section{Introduction}

Dramatic political changes took place in Hungary at the turn of the 1980s and 1990s (as in most other countries of Eastern and Central Europe), which changes were accompanied by a democratic transition and the significant changes in the system of the human rights of the country (Bielicki et al. 2005, Laska-Mierzejewska \& Olszewska 2006). A social restratification and the differentiation in the socioeconomic system - as the differences between the socioeconomic strata became more accentuated - associated with these systematic transitions. Moreover, significant economic and 
infrastructural differences appeared among the regions of the country, since the differences in the regional gross domestic product (GDP), the level of water and sewerage supply, the road network, etc., i.e. the differences in the macro-environmental factors increased among the regions. The increasing difference in the rate of unemployment among the regions during these decades also enhanced all these socioeconomic changes of the Hungarian society (Rona-Tas 1994, Tokes 1996, Philipov \& Dorbritz 2003). All these macro-environmental changes resulted in the increasing socioeconomic differences of the families.

To study the physical development of children is one of the most often used methods of human biology in checking the biological conditions of populations. It is evidenced by auxological surveys that the tempo and rate of maturation, as well as the timing and duration of the developmental phases are population-dependent and determined by environmental factors (Bielicki \& Welon 1982, Evelth \& Tanner 1990, Tanner 1992, Bodzsar \& Susanne 1998, Ellis 2004, Bodzsar 2006, Gluckman \& Hanson 2006). Socioeconomic conditions involving the access to material and social resources as well as reactions to stress-inducing conditions - e.g. the type of the region's settlements, the grade of urbanization, medical and educational resources and institutions, professional composition, regional social policy, etc. - play a decisive part as macroclimate in the processes of growth and maturation. All these influences reach the children through their environment and their family (Cusatis \& Shannon 1996, Neumark-Sztainer et al. 1999, De Bourdeaudhuij 2000, Bradley \& Corwyn 2002, Lien et al. 2002, Drukker et al. 2003, Vereecken et al. 2005).

The influence of these macro- and micro-environmental factors on the body development of children can mostly be manifest in puberty, in that interval of human postnatal life when the most intensive growth and maturation processes occur. Former studies on the relationship between socioeconomic environment and child development supported the general observation that remarkable differences exist in the body development of children of the same age but living in different socioeconomic backgrounds - if there are significant differences between the socioeconomic strata's nutritional, hygienic and health status in the studied population (Eiben 1972, Bodzsar 1975, Vercauteren \& Susanne 1985, Bodzsar 1991, Bodzsar 1998, Susanne \& Bodzsar 1998, Fredriks et al. 2000, Cole 2003, Mascie-Taylor \& Lasker 2005, Lipowicz et al. 2007). However, only few studies were carried out to analyse the sexual maturity pattern of children living in different socioeconomic backgrounds (Eiben 1972, Lindgren 1976, Bodzsar 1991, Onat \& Ertem 1995, Abioye-Kuteyi et al. 1997, Thomas et al. 2001, Codner et al. 2004, Ersoy et al. 2004, Braithwaite et al. 2009, Lehmann et al. 2010, Wronka 2010). The results of these studies evidenced later sexual maturation of children living in lower socioeconomic classes than their age-peers living in better socioeconomic conditions.

One of the most spectacular morphological changes in puberty is the development of the sex characteristics. The first menstruation, menarche in the girls and the first pollution, spermarche in the boys are important indicators of the new developmental stages of the reproductive system too. The biological indices of reproductive maturation, i.e. the timing of the respective stages of the secondary sex characteristics and the age at menarche and spermarche can be used as indicators of a population's or subpopulations' rate of sexual maturation (Eveleth \& Tanner 1990, Bodzsar 1991).

The change of the social system in the 1990s has brought about a serious deterioration of life standards for a considerable part of the people in Hungary. The differ- 
ences in the social and economic conditions of subsistence have grown between the social strata. In 2001 the Hungarian Cabinet named the regions that counted endangered and needed development (Hungarian Government 2001). The aim of the study was to find out whether essential differences exist in the sexual maturation pattern of Hungarian children living in the seriously deprived regions when compared to the Hungarian national reference values ( $2^{\text {nd }}$ Hungarian National Growth Study, HNGS II).

\section{Subjects and methods}

Altogether 711 girls and 790 boys (aged 10-16 years; Table 1) living in the deprived small regions of Hungary were examined between 2004 and 2007. Cabinet decree No. 24/2003 (Hungarian Government 2003) named a complex indicator to be formulated within the system of socioeconomic parameters, endangered small regions were graded by economic welfare indicators, e.g. the unemployment rate, industrial production, etc. Although it is evidenced that (1) the endangered and the not endangered regions of the country differed significantly in their macro-environmental indicators, and (2) the macro-environmental factors have considerable impact on the micro-environmental factors in the societies (e.g. unemployment ratio and parental occupation status; Dellve et al. 2006, Wendel-Vos et al. 2007, Bruga et al. 2008), the differences in the micro-environmental factors between the deprived and not deprived regions were studied in the beginning of the analysis. It is revealed that children living in the endangered small regions had higher risk to grow up in families having worse economic conditions than the average conditions in the society, the main socioeconomic differences were the followings:

- the family size in the deprived regions was significantly bigger, this difference can be attributed to the bigger number of children in the families (the frequency of families having 3 or more children was $31 \%$ in general in the Hungarian society and $45 \%$ in the deprived regions, $p: 0.041, \chi^{2}$ test),

- the frequency of families living smaller comfort level of the house/flat was $12 \%$ in general and $28 \%$ in the deprived regions $\left(p=0.005, \chi^{2}\right.$ test),

- the occupational level of the parents differed significantly between the national sample $(\mathrm{N})$ and the deprived regions (DR) in the categories of unemployed parents (fathers $-\mathrm{N}$ : $4 \%$, DR: $14 \%$, mothers - N: $10 \%$, DR: $24 \%$ ), the professionals (fathers $-\mathrm{N}: 14 \%$, DR: $7 \%$, mothers $-\mathrm{N}: 10 \%$, DR: $3 \%$ ), the technicians, associate professionals and clerical support workers (father - N: $6 \%$, DR: $3 \%$, mothers $-\mathrm{N}: 7 \%$, DR: $3 \%$ ), service and sales workers (fathers - N: $17 \%$, DR: $13 \%$, mothers - N: $28 \%$, DR: $24 \%$ ), agricultural workers (fathers $-\mathrm{N}: 4 \%$, DR: $8 \%$, mothers $-\mathrm{N}$ : $6 \%$, DR: $11 \%$ ), but not in the category of craft and related trades workers, machine operators, elementary occupations (fathers $-\mathrm{N}$ : $25 \%$, DR: $26 \%$, mothers - N: $24 \%$, DR: $26 \%$ ) and other occupational categories (the comparison of parental occupational distribution by $\chi^{2}$ test: fathers $-p=0.028$, mothers $-p=0.019$ ),

Table 1. Case numbers by age and gender.

\begin{tabular}{lccccrrrc}
\hline Age (ys) & $\mathbf{1 0}$ & $\mathbf{1 1}$ & $\mathbf{1 2}$ & $\mathbf{1 3}$ & $\mathbf{1 4}$ & $\mathbf{1 5}$ & $\mathbf{1 6}$ & Total \\
\hline Boys & 120 & 118 & 117 & 108 & 101 & 117 & 109 & 790 \\
Girls & 106 & 124 & 126 & 120 & 84 & 81 & 70 & 711 \\
\hline
\end{tabular}


- the educational level of parents also differed between the national and the regional samples (less than 8 years elementary schooling completed: fathers - N: $1 \%$, DR: $4 \%$, mothers $-\mathrm{N}: 1 \%$, DR: $5 \%$, elementary schooling completed: fathers - N: $7 \%$, DR: $17 \%$, mothers - N: $10 \%$, DR: $24 \%$, vocational school: fathers - N: $41 \%$, DR: $44 \%$, mothers N: $25 \%$, DR: $30 \%$, high school: fathers - N: $27 \%$, DR: $23 \%$, mothers $-\mathrm{N}: 38 \%$, DR: $25 \%$, university degree: fathers $-\mathrm{N}: 24 \%$, DR: $12 \%$, mothers $-\mathrm{N}: 26 \%$, DR: $16 \% ; p=$ 0.034 in fathers, $p=0.008$ in mothers in $\chi^{2}$ test),

- the mean per capita income (per year, in 2005) was 601,928 HUF was in the society, while 362,499 HUF in the deprived regions (data collection on the familiar income was prohibited in our survey, the source of these data: Hungarian Central Statistical Office 2008).

This general detriment in the economic status was accompanied by a socioeconomic drawback attributable to the lower parental education and occupation status in the families living in the endangered regions. All the macro-environmental influences reach the children through their micro-environment and as microclimate it is the family that mediates the economic functions and provides the care so essential for the physical existence of the child. Nutritional habits are the most important determinants among the lifestyle factors in the families that can have this moderator role between the socioeconomic status of the families and the developmental status of children. Therefore the nutrient supply and dietary habits of the endangered children was analysed by comparing them to the reference data of the $2^{\text {nd }}$ Hungarian National Growth Study (Bodzsar \& Zsakai 2012). Nutrient intake and dietary habits were estimated by the regularity of meals and by the reported daily calorie and nutrient intake. Our results evidenced that the social network could effectively work in the last decade, since the nutrition of children (aged between 3 and 18 years) living in the endangered regions differed neither in its qualitative nor in quantitative composition when compared to the national references.

Subjects' sexual maturity status was compared to the national reference values (HNGS II, Bodzsar \& Zsakai 2008, Bodzsar \& Zsakai 2012). Sexual maturity status in the girls was estimated by the stages of pubic hair ( $\mathrm{PH})$, axillary hair ( $\mathrm{AH})$ and breast development (B), as well as by the menarcheal status; while in the boys by the stages of pubic hair, axillary hair and genitalia development $(\mathrm{G})$, as well as by the spermarcheal status.

Sexual maturity status was estimated by the same researcher (by EB). The pubertal developmental stages of pubic hair, breast and genitalia were rated according to Tanner's recommendations (Tanner 1962). The stages of axillary hair were estimated by using Zeller's method (Zeller 1964). Data on menarcheal or spermarcheal status was collected by statusquo method. Statistical parameters of ages at menarche/spermarche and the occurrence of pubertal stages of sexual characteristics were estimated by probit analysis (M: median, SD: standard deviation, MAD: median absolute deviation, $95 \% \mathrm{CI}$ : $95 \%$ confidence interval of the median; Wilson \& Sutherland 1950, Weber 1969). To compare the age at the occurrence of menarche/spermarche as well as of the pubertal stages of sex characteristics the proportion of menarcheal/spermarcheal subjects (whose first menstruation/pollution had already occurred before the examinations) as well as the proportion of subjects being in the studied pubertal stages of sex characteristics was compared by $\chi^{2}$ test between the national sample and the endangered regions' sample. Cox regression analysis (Parker 1991) was also used to evaluate the effect of the socioeconomic status of the regions (deprived regions or the national references) on the age of menarche/spermarche and the age of occurrence of pubertal stages of the sexual characteristics. Hypotheses were tested at $5 \%$ level of random error by using SPSS v. 20.

\section{Results}

The sequence of sexual maturation events was similar in children living in the deprived regions compared to the national reference values (Figs 1-3, Tables 2-3): 

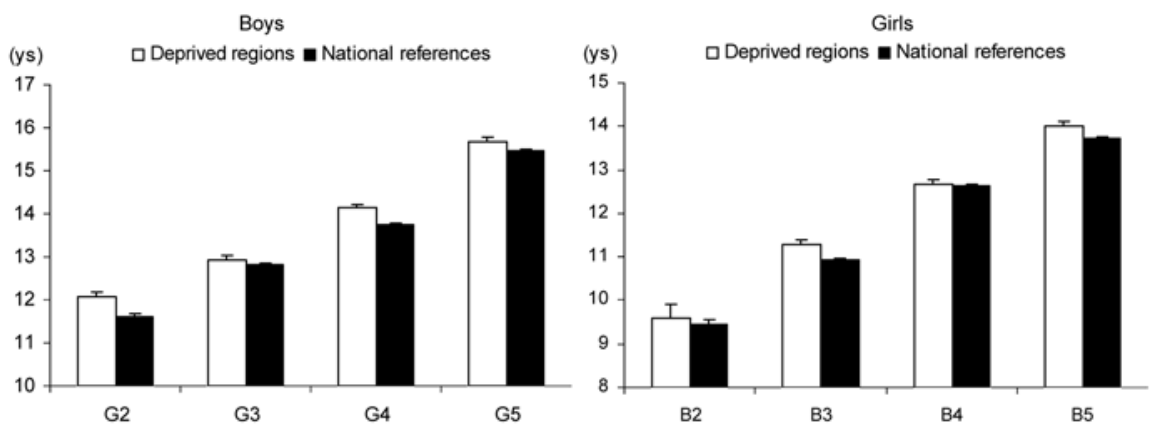

Fig. 1. Median age (+MAD) of Tanner stages of genitalia (boys, G2-5) and breast (girls, B2-5) development in children living in the deprived regions and the national reference values.
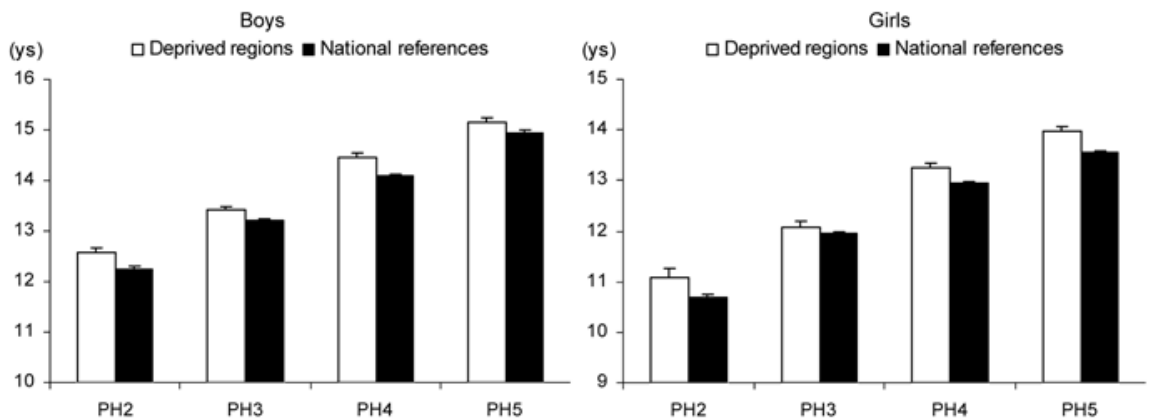

Fig. 2. Median age (+MAD) of Tanner stages of pubic hair development (PH2-5) in children living in the deprived regions and the national reference values.
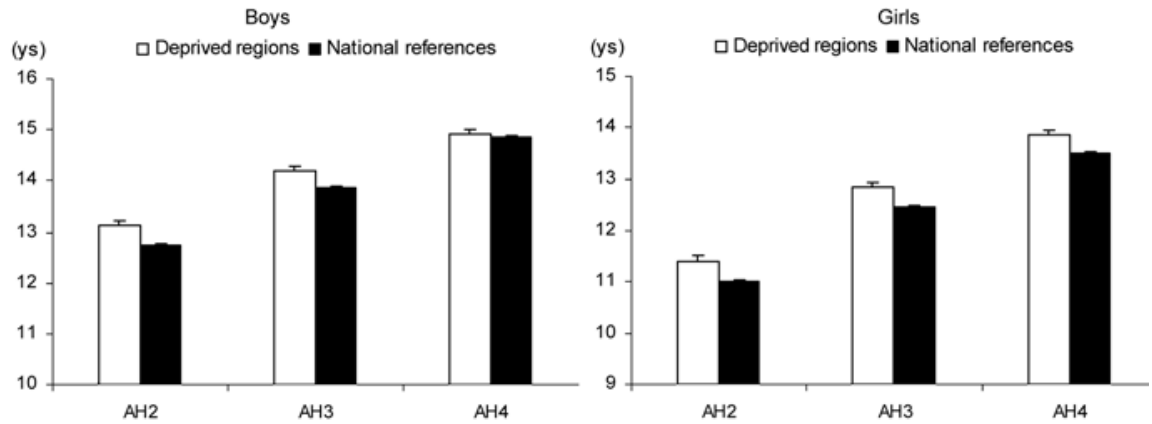

Fig. 3. Median age (+MAD) of Tanner stages of axillary hair development (AH2-5) in children living in the deprived regions and the national reference values. 
Table 2. Statistical parameters of being in the pubertal stages of the sexual characteristics (B: breast, PH: pubic hair, AH: axillary hair) and menarcheal age in girls living in the deprived regions and the national reference values $(*$ : significant difference, $p<0.05$; ns: not significant, $p>0.05-\chi^{2}$ test).

\begin{tabular}{lrrrrrrr}
\hline & \multicolumn{3}{c}{ Deprived regions } & \multicolumn{3}{c}{ National references } & \multirow{2}{*}{$\boldsymbol{p}$} \\
\cline { 2 - 7 } & $\mathbf{M}$ & \multicolumn{1}{c}{ SD } & \multicolumn{1}{c}{$\mathbf{9 5} \% \mathbf{C I}$} & \multicolumn{1}{c}{ M } & SD & $\mathbf{9 5 \%}$ CI & \\
\hline Menarcheal age & 13.05 & 1.25 & $12.89-13.21$ & 12.79 & 1.16 & $12.78-12.81$ & $*$ \\
B2 & 9.61 & 1.15 & $9.05-10.17$ & 9.44 & 1.10 & $9.15-9.73$ & $*$ \\
B3 & 11.30 & 1.38 & $11.08-11.52$ & 10.93 & 1.45 & $10.87-10.99$ & $*$ \\
B4 & 12.67 & 1.28 & $12.49-12.85$ & 12.64 & 1.17 & $12.63-12.65$ & ns \\
B5 & 14.00 & 1.32 & $13.79-14.20$ & 13.71 & 1.30 & $13.66-13.76$ & $*$ \\
PH2 & 11.08 & 1.14 & $10.71-11.46$ & 10.68 & 1.07 & $10.49-10.87$ & $*$ \\
PH3 & 12.09 & 1.30 & $11.86-12.32$ & 11.96 & 1.18 & $11.92-12.01$ & ns \\
PH4 & 13.25 & 1.42 & $13.06-13.45$ & 12.96 & 1.23 & $12.93-12.98$ & $*$ \\
PH5 & 13.97 & 1.36 & $13.75-14.18$ & 13.56 & 1.42 & $13.48-13.64$ & $*$ \\
AH2 & 11.40 & 1.18 & $11.15-11.65$ & 11.02 & 1.12 & $10.93-11.10$ & $*$ \\
AH3 & 12.84 & 1.28 & $12.50-13.03$ & 12.44 & 1.25 & $12.41-12.46$ & $*$ \\
AH4 & 13.85 & 1.37 & $13.63-14.07$ & 13.49 & 1.14 & $13.45-13.53$ & $*$ \\
\hline
\end{tabular}

Table 3. Statistical parameters of being in the pubertal stages of the sexual characteristics (G: genitalia, PH: pubic hair, AH: axillary hair) and spermarcheal age in boys living in the deprived regions and the national reference values ( $*$ : significant difference, $p<0.05$; ns: not significant, $p>0.05-\chi^{2}$ test).

\begin{tabular}{lccccccc}
\hline & \multicolumn{3}{c}{ Deprived regions } & \multicolumn{3}{c}{ National references } & \multirow{2}{*}{$\boldsymbol{p}$} \\
\cline { 2 - 7 } & $\mathbf{M}$ & SD & $\mathbf{9 5} \% \mathbf{C I}$ & $\mathbf{M}$ & SD & $\mathbf{9 5 \%}$ CI & \\
\hline Spermarcheal & 14.26 & 1.44 & $14.08-14.44$ & 13.92 & 1.31 & $13.51-14.34$ & $*$ \\
age & & & & & & & \\
G2 & 12.07 & 1.27 & $11.84-12.30$ & 11.62 & 1.12 & $11.46-11.78$ & $*$ \\
G3 & 12.93 & 1.61 & $12.76-13.11$ & 12.82 & 1.44 & $12.74-12.89$ & ns \\
G4 & 14.13 & 1.19 & $13.96-14.29$ & 13.76 & 1.21 & $13.70-13.82$ & $*$ \\
G5 & 15.68 & 1.34 & $15.46-15.89$ & 15.46 & 1.43 & $15.35-15.57$ & $*$ \\
PH2 & 12.58 & 1.12 & $12.39-12.77$ & 12.25 & 1.01 & $12.18-12.32$ & $*$ \\
PH3 & 13.42 & 0.92 & $13.25-13.58$ & 13.22 & 0.88 & $13.16-13.28$ & $*$ \\
PH4 & 14.46 & 0.95 & $14.29-14.62$ & 14.09 & 0.91 & $14.03-14.15$ & $*$ \\
PH5 & 15.14 & 1.25 & $14.97-15.31$ & 14.95 & 1.28 & $14.83-15.07$ & $*$ \\
AH2 & 13.13 & 1.29 & $12.95-13.30$ & 12.74 & 1.08 & $12.66-12.82$ & $*$ \\
AH3 & 14.19 & 1.16 & $14.03-14.36$ & 13.87 & 1.15 & $13.83-13.92$ & $*$ \\
AH4 & 14.90 & 1.27 & $14.72-15.07$ & 14.85 & 1.42 & $14.76-14.94$ & ns \\
\hline
\end{tabular}

- The first visible sign of sexual maturation was the budding of breast (B2) in the girls, while the start of testicular enlargement (G2) in the boys.

- The median age of the beginning of pubic hair development (PH2) was slightly higher than the median age of B2/G2 stages in the girls and boys, respectively, but the median age of the last stage of pubic hair development (PH5) was lower than the corresponding stage for either breast or male genital development (B5/G5). In general, girls are more advanced in sexual maturation than boys of the same age. 
- The first pubertal stage of axillary hair development generally occurred as the 2nd pubertal stage of breast or male genital development (B3/G3) developed ( \pm 1 month later and older, respectively).

- As a tendency it was found that the intervals between the median ages of the first and last pubertal stages of the comparable sexual characteristics were in general 3-9 months shorter in the boys than in the girls (girls - PH2-5: 2.9 ys, AH: 2.4 ys; boys - PH2-5: 2.6 ys, AH: 1.8 ys, Table 5).

- Menarche occurred around the stage 4 of the breast and pubic hair development, while spermarche around the stage 4 of genitalia and pubic hair development.

Both the first menstruation and the first pollution occurred a bit later $(\sim 2$ months later in the girls and $\sim 4$ months later in the boys; Tables $2-3$ ) in children living in the deprived regions than the national reference values.

By comparing to the national reference values the developmental stages of sexual characteristics in children living in the deprived regions occurred in older ages, generally with 1-3 months later (there were significant differences between the deprived regions and the national standards in the occurrence of these stages with only few exceptions; Tables 2-4). The interval between the median ages of the first and last pubertal stages was similar in the subjects living in deprived regions of Hungary compared to the national reference values (Table 5). However, not only the total intervals between the first and last pubertal stages were similar, but also the subintervals (i.e. the time required for the stages' development) between the consecutive stages of sexual characteristics were very similar in the national and deprived samples. This similarity suggests that the significant disadvantage in the macro-environmental factors of the deprived regions could not influence, in this case could not increase considerably the time that is necessary for the developmental processes of sexual maturation, i.e. for the development of the sexual characteristics compared to the sexual

Table 4. The association between the occurrence of pubertal stages of the sexual characteristics (B: breast, G: genitalia, PH: pubic hair, AH: axillary hair) and menarcheal/spermarcheal $(\mathrm{M} / \mathrm{S})$ age and the socioeconomic status of the regions (deprived regions or the national reference) by using Cox regression analysis ( $\beta$ : regression coefficient, SE: standard error, $95 \%$ CI: $95 \%$ confidence interval for $\exp (\beta)$ or hazard ratio, $p$ : significance level, Italic $p$-values indicate significant associations).

\begin{tabular}{lcccc|cccc}
\hline & \multicolumn{3}{c|}{ Girls } & \multicolumn{4}{c}{ Boys } \\
\cline { 2 - 9 } & $\beta$ & SE & $\mathbf{9 5} \% \mathbf{C I}$ & $\mathbf{p}$ & $\beta$ & SE & $\mathbf{9 5} \% \mathbf{C I}$ & $\boldsymbol{p}$ \\
\hline M/S age & 0.184 & 0.052 & $1.085-1.331$ & $<0.001$ & 0.171 & 0.049 & $0.828-1.005$ & 0.044 \\
B/G2 & 0.547 & 0.104 & $1.411-2.118$ & $<0.001$ & 0.245 & 0.118 & $1.013-1.611$ & 0.039 \\
B/G3 & 0.480 & 0.080 & $1.381-1.890$ & $<0.001$ & 0.710 & 0.122 & $0.844-1.364$ & 0.564 \\
B/G4 & 0.006 & 0.111 & $0.810-1.249$ & 0.957 & 0.306 & 0.082 & $1.158-1.594$ & 0.001 \\
B/G5 & 0.227 & 0.065 & $1.104-1.426$ & 0.001 & 0.152 & 0.070 & $0.827-1.289$ & 0.045 \\
PH2 & 0.569 & 0.106 & $1.436-2.172$ & $<0.001$ & 0.175 & 0.128 & $0.838-1.387$ & 0.057 \\
PH3 & 0.365 & 0.165 & $1.043-1.990$ & 0.047 & 0.230 & 0.124 & $0.988-1.604$ & 0.037 \\
PH4 & 0.378 & 0.124 & $1.145-1.861$ & 0.002 & 0.212 & 0.115 & $0.986-1.548$ & 0.046 \\
PH5 & 0.202 & 0.068 & $1.072-1.397$ & 0.003 & 0.148 & 0.063 & $0.842-1.480$ & 0.043 \\
AH2 & 0.450 & 0.101 & $1.286-1.913$ & $<0.001$ & 0.409 & 0.101 & $1.236-1.835$ & $<0.001$ \\
AH3 & 0.297 & 0.122 & $1.060-1.709$ & 0.015 & 0.190 & 0.120 & $0.744-1.491$ & 0.046 \\
AH4 & 0.244 & 0.064 & $1.126-1.446$ & $<0.001$ & 0.019 & 0.060 & $0.897-1.134$ & 0.883 \\
\hline
\end{tabular}


Table 5. Interval between the median age (ys) of the development of the first and last pubertal stages in sexual characteristics in children living in the deprived regions and the national reference values.

\begin{tabular}{lcc}
\hline & Deprived regions & National references \\
\hline Girls & & \\
B2-5 & 4.39 & 4.27 \\
PH2-5 & 2.89 & 2.88 \\
AH2-4 & 2.45 & 2.47 \\
\hline Boys & & \\
G2-5 & 3.61 & 3.84 \\
PH2-5 & 2.56 & 2.70 \\
AH2-4 & 1.77 & 2.11 \\
\hline
\end{tabular}

maturity pattern estimated for the Hungarian population in the first decade of the 2000s.

\section{Conclusions}

The analysis of the nutritional status of children (aged between 3 and 18 years) living in the deprived regions revealed that the prevalence of underweight was significantly higher in children living in the deprived regions than the national reference values while the prevalence of overweight and obese children did not differ between deprived regions and the national reference values (Bodzsar et al. 2012, Bodzsar \& Zsakai 2012). It is evidence that nutritional status might interfere with the tempo of sexual maturation, therefore we continued our study with the analysis of sexual maturity pattern of children living in the deprived regions in the mirror of the national reference values.

The sequence of pubertal maturation events and the length of sexual maturation were very similar in pubertal children living in the seriously deprived regions compared to the national reference values in the present analysis. However, the timing of pubertal development in children from the deprived regions showed a small shift toward older ages compared to the national reference values. These results are in accordance with the observations of the other auxological surveys on the sexual maturity pattern of children living in lower socioeconomic strata or in deprived regions - later sexual maturity of disadvantaged children was evidenced if significant socioeconomic differences existed between the studied strata or regions (Eiben 1972, Lindgren 1976, Bodzsar 1991, Onat \& Ertem 1995, Abioye-Kuteyi et al. 1997, Thomas et al. 2001, Codner et al. 2004, Ersoy et al. 2004, Wronka \& PawlinskaChmara 2005, Bektas 2008, Braithwaite et al. 2009, Szwed et al. 2013).

However, by considering the later sexual maturation of children living in the deprived regions when compared to the national reference values and the results of auxological surveys from other European countries carried out to study the socioeconomic differences of sexual maturation pattern, a contrasting evidence on children from low socioeconomic strata who developed at faster pace than children from upper social classes could be found as well (e.g. in the United Kingdom and Germany, Kahl et al. 2007, Murphy et al. 2013). The higher rate of migrants in the lower 
socioeconomic strata, therefore their different genetic backgrounds and differences in the nutritional status between the migrant and not migrant groups in the populations could reflect in this opposite relation of SES and sexual maturation tempo.

The worse nutritional status and the retardation in sexual maturation of children and adolescents living in the deprived regions of Hungary compared to the national reference values emphasize that the environmental risk factors (housing quality, educational facilities, work environment, neighbourhood conditions, etc.) of the seriously deprived regions are still at high level and the need of complex socioeconomic amelioration of the regions. The results of our study can provide reliable data on the basis of which recommendations can be formulated and measures applicable in social, medical and public welfare policy can be shaped.

\section{Acknowledgements}

The study was supported by the Hungarian National Foundation for Science (OTKA grants K 47073 , K 76849).

\section{References}

Abioye-Kuteyi, E., Ojofeitimi, E.O., Aina, O.I., Kio, F., Aluko, Y. \& Mosuro, O. (1997): The influence of socioeconomic and nutritional status on menarche in Nigerian school girls. Nutr. Health 11 (3): 185-195.

Bektas, Y. (2008): Age at Menarche in Ankara, Turkey. - Anthropol. Kozl. 49: 51-59.

Bielicki, T. \& Welon, Z. (1982): Growth data as indicators of social inequalities: the case of Poland. - Yb. Phys. Anthropol. 25: 153-167.

Bielicki, T., Szklarska, A., Koziel, S. \& Ulijaszek, S.J. (2005): Changing patterns of social variation in stature in Poland: Effects of transition from a command economy to the freemarket system? - J. Biosoc. Sci. 37 (4): 427-434.

Bodzsar, E.B. (1975): Data to puberty of girls. - Humanbiol. Budapest. 3. pp. 1-198.

Bodzsar, E.B. (1991): The Bakony Growth Study. Humanbiologia Budapestinensis 22. - Eotvos University Press, Budapest.

Bodzsar, E.B. (1998): Secular growth changes in Hungary. - In: Bodzsar, E.B. \& Susanne, C. (eds): Secular Growth Changes in Europe. - Eotvos University Press, Budapest, pp. 175205.

Bodzsar, E.B. (2006): Secular change in growth and sexual maturation of Hungarian children. - Int. J. Anthropol. 21 (1): 25-32.

Bodzsar, E.B. \& Susanne, C. (1998): Secular Growth Changes in Europe. - Eotvos University Press, Budapest. pp. 1-381.

Bodzsar, E.B. \& Zsakai, A. (2008): Secular changes in the pattern of growth in Hungarian children (in Hungarian with English abstract). - Anthropol. Kozl. 49: 75-93.

Bodzsar, E.B. \& Zsakai, A. (2012): Body developmental status of Hungarian children and adolescents. Hungarian National Growth Study 2003-2006. - Plantin Press, Budapest.

Bodzsar, E.B., Zsakai, A. \& Tausz, K. (2012): The body structure and the health status of children living in the disadvantaged micro-regions of Hungary. - Anthropol. Kozl. 53: 95-108.

Bradley, R.H. \& Corwyn, R.F. (2002): Socio-economic status and child development. Annu. Rev. Psychol. 53: 371-399.

Braithwaite, D., Moore, D.H., Lustig, R.H., Epel, E.S., Ong, K.K., Rehkopf, D.H., Wang, M. C., Miller, S.M. \& Hiatt, R.A. (2009): Socioeconomic status in relation to early menarche among black and white girls. - Cancer Cause Control 20: 713-720. 
Bruga, J., Kremersa, S.P., van Lenthea, F., Balla, K. \& Crawforda, D. (2008): Environmental determinants of healthy eating: in need of theory and evidence. - Proc. Nutr. Soc. 67 (3): 307-316.

Codner, E., Unanue, N., Gaete, X., Barrera, A., Mook-Kanamir, D., Bazaes, R., Avila, A. \& Cassorla, F. (2004): Age of pubertal events in Chilean school age girls and its relationship with socioeconomic status and body mass index. - Rev. Med. Chile 132 (7): 801-808.

Cole, T.J. (2003): The secular trend in human physical growth: a biological view. - Econ. Hum. Biol. 1 (2): 161-168.

Cusatis, D.C. \& Shannon, B.M. (1996): Influences of adolescent eating behaviour. - J. Adolescent Health 18: 27-34.

De Bourdeaudhuij, I. \& Van Oost, P. (2000): Personal and family determinants of dietary behaviour in adolescents and their parents. - Psychol. Health 15: 751-770.

Dellve, L., Karlberg, C., Allebeck, P., Herloff, B. \& Hagberg, M. (2006): Macro-organizational factors, the incidence of work disability, and work ability among the total workforce of home care workers in Sweden. - Scand. J. Public Health 34 (1): 17-25.

Drukker, M., Kaplan, C., Feron, F. \& van Os, J. (2003): Children's health-related quality of life, neighbourhood socio-economic deprivation and social capital. - Soc. Sci. Med. 57: 825-841.

Eiben, O.G. (1972): Genetische und demografische Faktoren und Menarchealter. - Anthropol. Anz. 33: 205-211.

Ellis, B.J. (2004): Timing of pubertal maturation in girls: An integrated life history approach. - Psychol. Bull. 130 (6): 920-958.

Ersoy, B., Balkan, C., Gunay, T., Onag, A. \& Egemen, A. (2004): Effects of different socioeconomic conditions on menarche in Turkish female students. - Early Hum. Dev. 76 (2): $115-125$.

Eveleth, P.B. \& Tanner, J.M. (1990): Worldwide Variation in Human Growth. - Cambridge University Press, Cambridge.

Fredriks, A.M., van Buuren, S., Burgmeier, R.J.F., Meulmeester, J.F., Beuker, R.J., Brugman, E., Roede, M.J., Verloove-Vanhorick, P. \& Wit, J.M. (2000): Continuing positive secular growth change in the Netherlands 1955-1997. - Pediatr. Res. 47: 316-323.

Gluckman, P.D. \& Hanson, M.A. (2006): Evolution, development and timing of puberty. Trends Endocrin. Met. 17 (1): 7-12.

Hungarian Government (2001): Government Decree No 91/2001 (VI.15.) on the list of beneficiary micro-regions of regional development (in Hungarian).

Hungarian Government (2003): Government Decree No 24/2003 (III.4.) on the regional governance of sustainable integrated development of deprived micro-regions (in Hungarian).

Hungarian Central Statistical Office (2008): The deprived small regions of Hungary (in Hungarian). - Hungarian Central Statistical Office, Budapest.

Kahl, H., Schaffrath, R.A. \& Schlaud, M. (2007): Sexual maturation of children and adolescents in Germany. Results of the German Health Interview and Examination Survey for Children and Adolescents (KiGGS). - Bundesgesundheitsblatt - Gesundheitsforschung Gesundheitsschutz 50 (5-6): 677-685.

Laska-Mierzejewska, T. \& Olszewska, E. (2006): Changes in the biological status of Polish girls from a rural region associated with economic and political processes in the period 1967-2001. - J. Biosoc. Sci. 38: 187-202.

Lehmann, A., Scheffler, Ch. \& Hermanussen, M. (2010): The variation in age at menarche: an indicator of historic developmental tempo. - Anthropol. Anz. 68 (1): 85-99.

Lien, N., Jacobs, D.R. \& Klepp, K.-I. (2002): Exploring predictors of eating behaviour among adolescents by gender and socio-economic status. - Public Health Nutr. 5: 671681.

Lindgren, G. (1976): Height, weight and menarche in Swedish urban school children in relation to socio-economic and regional factors. - Ann. Hum. Biol. 3 (6): 501-528. 
Lipowicz, A., Koziel, S., Hulanicka, B. \& Kowalisko, A. (2007): Socioeconomic status during childhood and health status in adulthood: The Wroclaw Growth Study. - J. Biosoc. Sci. 39 (4): 481-491.

Mascie-Taylor, C.G.N. \& Lasker, G.W. (2005): Biosocial correlates of stature in a British national cohort. - J. Biosoc. Sci. 37 (2): 245-251.

Murphy, L., Sievert, L., Begum, K., Sharmeen, T., Puleo, E., Chowdhury, O., Muttukrishna, S. \& Bentley, G. (2013): Life course effects on age at menopause among Bangladeshi sedentees and migrants to the UK. - Am. J. Hum. Biol. 25 (1): 83-93.

Neumark-Sztainer, D., Story, M., Perry, C. \& Casey, M.-A. (1999): Factors influencing food choices of adolescents: Findings from focus-group discussion with adolescents. - J. Am. Diet. Assoc. 99 (8): 929-937.

Onat, T. \& Ertem, B. (1995): Age at menarche: Relationship to socioeconomic status, growth rate in stature and weight, and sexual maturation. - Am. J. Hum. Biol. 7 (6): 741-750.

Parker, R.E. (1991): Introductory Statistics for Biology. $2^{\text {nd }}$ ed. - Cambridge University Press, Cambridge.

Philipov, D. \& Dorbritz, J. (2003): Demographic consequences of economic transition in countries of Central and Eastern Europe. Population studies, 39. - Strasburg, Council of Europe Publishing.

Rona-Tas, A. (1994): The First Shall Be Last? Entrepreneurship and Communist Cadres in the Transition from Socialism. - Am. J. Sociol. 100 (1): 40-69.

Susanne, C. \& Bodzsar, E.B. (1998): Patterns of secular change of growth and development. - In: Bodzsar, E.B. \& Susanne, C. (eds): Secular Growth Changes in Europe. - Eotvos University Press, Budapest, pp. 5-26.

Szwed, A., John, A., Czapla, Z. \& Kosinska, M. (2013): Influence of socioeconomic factors on age at menarche of Polish girls. - Anthropol. Anz. 70 (4): 455-470.

Tanner, J.M. (1962): Growth at adolescence (2nd ed). - Blackwell Sci. Publ., Oxford, p. 326.

Tanner, J.M. (1992): Growth as a measure of the nutritional and hygienic status of a population. - Horm. Res. 38: 106-115.

Thomas, F., Renaud, F., Benefice, E., de Meeus, T. \& Guegan, J.-F. (2001): International variability of ages at menarche and menopause: Patterns and main determinants. - Hum. Biol. 73 (2): 271-290.

Tokes, R. (1996): Political Transition and Social Transformation in Hungary. - Afers Int. 3435: 79-101.

Vercauteren, M. \& Susanne, C. (1985): The secular trend of height and menarche in Belgium: are there any signs of a future stop? - Eur. J. Pediatr. 144 (4): 306-309.

Vereecken, C.A., Inchley, J., Subramanian, S.V., Hublet, A. \& Maes, L. (2005): The relative influence of individual and contextual socio-economic status on consumption of fruit and soft drinks among adolescents in Europe. - Eur. J. Public Health 15: 224-232.

Weber, E. (1969): Grundriss der biologischen Statistik (5. Auflage). - Fischer Verlag, Jena, pp. 81-86.

Wendel-Vos, W., Droomers, M., Kremers, S., Brug, J. \& Van Lenthe, F. (2007): Potential environmental determinants of physical activity in adults: a systematic review. - Obes. Rev. 8 (5): 425-440.

Wilson, D.C. \& Sutherland, I. (1950): Further observation on the age at menarche. - Brit. Med. J. 2: 862-866.

Wronka, I. (2010): Association between BMI and age at menarche in girls from different socio-economic groups. - Anthropol. Anz. 68 (1): 43-52.

Wronka, I. \& Pawlinska-Chmara, R. (2005): Menarcheal age and socio-economic factors in Poland. - Ann. Hum. Biol. 32 (5): 630-638.

Zeller, W. (1964): Konstitution und Entwicklung. - Verlag für Psychologie, Göttingen. 
Submitted: 23 January 2014; accepted: 16 April 2014.

Address for correspondence: Annamaria Zsakai, Department of Biological Anthropology, Eotvos Lorand University, 1117 Budapest, Pazmany P. s. 1/c, Hungary bodzsar@elte.hu

zsakaia@elte.hu 